View Journal | View Issue

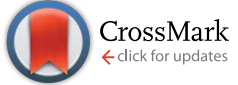

Cite this: RSC Adv., 2015, 5, 48413
Received 19th April 2015

Accepted 21st May 2015

DOI: $10.1039 / c 5 r a 07080 e$

www.rsc.org/advances

\section{Toward bioenergy recovery from waste activated sludge: improving bio-hydrogen production and sludge reduction by pretreatment coupled with anaerobic digestion-microbial electrolysis cells}

\begin{abstract}
Zhangwei He, ${ }^{a}$ Aijuan Zhou, ${ }^{\text {ac }}$ Chunxue Yang, ${ }^{a}$ Zechong Guo, ${ }^{a}$ Aijie Wang, ${ }^{\text {*ab }}$ Wenzong Liu*b and Jun Nan ${ }^{a}$

In this study, a novel technology named pretreatment coupled with anaerobic digestion-microbial electrolysis cells (AD-MECs) for waste activated sludge (WAS) reduction and renewable bioenergy recovery has been investigated. The results showed that, compared with the control pretreatment, the three pretreatment methods used greatly enhanced the performance of the AD-MECs process, and efficient sludge reduction was achieved, especially in heat-alkaline pretreatment, $36.9 \%$ and $46.7 \%$ for total suspended solid (TSS) and volatile suspended solid (VSS) removal in 6 days. MECs fed with fermented WAS, displayed positive potential for bioenergy recovery, and the highest bio-hydrogen yield was $20.30 \mathrm{mg} \mathrm{H}_{2} / \mathrm{g}$ VSS. Kinetic models indicated that with initial concentrations of soluble organic matter increasing, the bio-hydrogen yields of MECs increased linearly $\left(R^{2}=0.8903-0.9742\right)$. The results above suggested that the novel technology proposed in this work showed attractive potential for renewable bioenergy recovery and sludge reduction.
\end{abstract}

\section{Introduction}

Industrialisation and the current population growth have led to rapidly increasing energy consumption. ${ }^{1}$ In $2008,88 \%$ of the worlds energy demand was supplied by fossil fuels, such as oil (35\%), coal $(29 \%)$ and natural gas $(24 \%)^{2}{ }^{2}$ However, the depletion of coal supplies is predicted by 2112 , and depletion of oil and gas reserves by 2042 , thus, a rapid transition to renewable energy is needed in the near future. ${ }^{3}$ Based on renewable energy production and emissions reduction of greenhouse gases, energy dependency, associated with fossil fuels, has made anaerobic digestion (AD) of renewable biomass as an attractive option. ${ }^{4,5}$ Thus, biogas, especially bio-hydrogen, produced from renewable biomass by the potential means of the $\mathrm{AD}$ process has received intense attention. ${ }^{6,7}$

Recently, waste activated sludge (WAS) as the operation byproduct of wastewater treatment plants (WWTPs), its production has been increased significantly with the rapid development of

\footnotetext{
${ }^{a}$ State Key Laboratory of Urban Water Resource and Environment, Harbin Institute of Technology (SKLUWRE, HIT), P.O. Box 2614, 202 Haihe Road, Harbin 150090, China. E-mail: waj0578@hit.edu.cn; Fax: +86-451-86282195; Tel: +86-451-86282195

${ }^{b}$ Key Laboratory of Environmental Biotechnology, Research Center for EcoEnvironmental Sciences, Chinese Academy of Sciences, 18 Shuangqing Road, Haidian District, Beijing, 100085, China.E-mail: wzliu@rcees.ac.cn; Fax: +86-45186282110; Tel: +86-451-86282110

${ }^{c}$ College of Environmental Science and Engineering, Taiyuan University of Technology, Taiyuan, China
}

population and urbanization., ${ }^{\mathbf{8} 9}$ At present, although some approaches (landfill, incineration, land-use, etc.) could effectively solve the WAS problems, the effects followed are not friendly to both environment and ecosystem. ${ }^{\mathbf{1 , 1 0 , 1 1}}$ Meanwhile, costs of treatment methods mentioned above are very high, accounting for approximately $40-60 \%$ operation cost of WWTPs. ${ }^{10}$ Thus, it is particularly important to develop effective and environmental techniques for WAS treatment.

The WAS can be used as a source of valuable chemical productions, but the main feature may be as promising feedstocks for renewable biofuels. ${ }^{1}$ Currently, lots of researches have investigated the efficiencies of biogas and nutrients recoveries by $\mathrm{AD}$ process from WAS. ${ }^{1,7-15}$ However, it is well known that WAS hydrolysis is the rate-limiting step, resulting in low efficiency but high cost. $^{8-15}$ With the purpose to enhance the performance of $\mathrm{AD}$ process, a series of researches on WAS pretreatment have been done, aiming to improve WAS hydrolysis, such as biological, chemical, mechanical and codigestion, etc. ${ }^{\mathbf{9}, \mathbf{1 2 , 1 6 - 1 8}}$ In order to further improve WAS utilization, some previous studies have reported that it is possible to make the fermented liquid (mainly consisted of soluble protein, soluble carbohydrate, volatile fatty acids (VFAs), etc.) of WAS as the substrates for microbial electrolysis cells (MECs) to produce bio-hydrogen. ${ }^{19,20}$ However, one significant shortage of above researches is that the efficiency of sludge reduction has not been investigated. And another is that, though the positive effects of bioenergy recovery can be achieved, membrane 
filtration of fermented WAS is needed, while using the fermented liquid as the substrate for MECs, which leads to complicate bio-hydrogen production line and increase operation cost. Therefore, it is essential and meaningful to look for innovation and improved process.

Based on the knowledge obtained from previous investigations, making fermented WAS as the substrate of MECs directly for bio-hydrogen production, on one hand, could enhance the buffering capacity of the $\mathrm{AD}$ process, improve bioenergy production, and increase the positive synergisms established in the digesters, on the other hand, would improve the utilization efficiency of existing digesters at WWTPs and reduce the collection and transport cost of other decentralized organic matter. ${ }^{\mathbf{1 3 , 2 1}}$ However, little information is available regarding the pretreatment coupled with $\mathrm{AD}$-MECs for bioenergy recovery and sludge reduction.

This work proposes to investigate the performances of pretreatment coupled with $\mathrm{AD}-\mathrm{MEC}$ for sludge reduction and bioenergy recovery, while WAS is used as the substrate. The outcome of this study will establish some fundamentals that permit on the further exploration of novel bioenergy recovery and sludge reduction technique for the potential improvement of $\mathrm{AD}$ process.

\section{Materials and methods}

\subsection{WAS source and characteristics}

WAS used in this study was taken from the secondary sedimentation tank of Taiping Municipal Wastewater Treatment Plant running with anaerobic-anoxic-aerobic $\left(\mathrm{A}^{2} / \mathrm{O}\right)$ system, Harbin, China. The WAS firstly was thickened by gravitational sedimentation for $24 \mathrm{~h}$ at $4{ }^{\circ} \mathrm{C}$, then screened with a $1 \mathrm{~mm}$ sieve to remove impurities, finally stored at $4{ }^{\circ} \mathrm{C}$ prior for later use and test. The main characteristics of WAS were: total suspended solids (TSS) $15.23 \mathrm{~g} \mathrm{~L}^{-1}$, volatile suspended solids (VSS) $8.03 \mathrm{~g}$

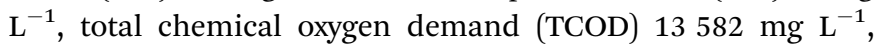
soluble chemical oxygen demand (SCOD) $267 \mathrm{mg} \mathrm{L}^{-1}$, soluble protein $14 \mathrm{mg}$ COD per L, soluble carbohydrate $13.53 \mathrm{mg}$ COD per L, VFAs $210 \mathrm{mg}$ COD per L and pH 6.92.

\subsection{Potential technique for waste activated sludge treatment}

In this study, in order to simplify the previously employed processes for bio-hydrogen production, ${ }^{\mathbf{1 9 , 2 0}}$ the fermented WAS obtained after 3 day anaerobic fermentation was directly added to MECs to produce hydrogen. The detailed technological process was shown in Fig. 1. Firstly, three typical pretreatment methods (heat-alkaline, freeze-thaw and ultrasonication) were used to pretreat WAS respectively to enhance WAS hydrolysis. Secondly, each pretreated WAS was fermented by a continuous stirred tank reactor (CSTR) under anaerobic condition to enhance concentrations of soluble organic matters (mainly soluble protein, soluble carbohydrate, and VFAs, especially VFAs). Thirdly, fermented WAS was directly added into MECs to produce hydrogen. The whole process was named pretreatment coupled with $\mathrm{AD}-\mathrm{MECs}$ process, which might be a positively potential technique for sludge reduction and renewable energy recovery from WAS.

2.2.1 Pretreatment methods. The detailed conditions for WAS pretreatment methods were: (1) the control was operated simultaneously with no pretreatment to WAS. (2) the heatalkaline pretreatment was carried out by firstly adding $\mathrm{NaOH}$ with dosage $0.105 \mathrm{~g} \mathrm{~g}^{-1} \mathrm{VSS}$, then keeping $81{ }^{\circ} \mathrm{C}$ for 20 minutes. ${ }^{23}$ (3) The freeze-thaw pretreatment was carried out by firstly freezing at $-18{ }^{\circ} \mathrm{C}$ for $72 \mathrm{~h}$, then thawing at ambient temperature, $22 \pm 2{ }^{\circ} \mathrm{C}^{24}$ (4) The ultrasonication pretreatment was carried out with power density $0.5 \mathrm{~W} \mathrm{~mL}^{-1}$ for 10 minutes. $^{25}$ All treatments above were carried out in triplicate.

2.2.2 Anaerobic digestion set-up and operations. The CSTR, whose maximum working volume was $2.0 \mathrm{~L}$, was used as anaerobic fermentation reactor. And the working volume was 1.0 L in this work. The operation conditions were: temperature $35 \pm 2{ }^{\circ} \mathrm{C}$, stirring rate $110-120 \mathrm{rpm}$, sludge retention time (SRT) 72 h. ${ }^{26}$ Nitrogen gas was introduced to the reactors for 15 min to remove oxygen, and all tests were also carried out in triplicate.

2.2.3 MECs set-up and operations. MECs used in this study were set up on the basis of previous study. ${ }^{19}$ And the working volume was $40 \mathrm{~mL}$, including a $28 \mathrm{~mL}$ chamber $(3 \mathrm{~cm}$ diameter $\times 4 \mathrm{~cm}$ length) and a $10 \mathrm{~mL}$ injection syringe (total volume $12 \mathrm{~mL}$ ). The detailed parameters of anode and cathode can be found in the previous publication. ${ }^{20}$ In this work, there were 12 single chamber MECs. The MECs were inoculated by WAS mentioned in Section 2.1 and were fed with acetate in start-up stage. ${ }^{28}$ The detailed information on start-up of MECs could be found in the research of Liu et al. ${ }^{19}$ After the start-up of MECs, every 3 MECs were operated in parallel, resulting in four groups, named control, heat-alkaline, freeze-thaw and ultrasonication pretreatments, respectively. Then fermented WAS was used as carbon source for hydrogen production in $72 \mathrm{~h}$ batch operations. All MECs were synchronously operated for three cycles. And the operation temperature were $22 \pm 2{ }^{\circ} \mathrm{C}$, ambient temperature.

\subsection{Analytical methods}

WAS samples were centrifuged at $10000 \mathrm{rpm}$ for 10 minutes, then supernatant samples were filtered by $0.45 \mu \mathrm{m}$ cellulose nitrate membrane filters and finally filtrated samples were stored at $4{ }^{\circ} \mathrm{C}$ prior to analysis, of which, the VFAs, soluble carbohydrate and protein were analyzed immediately. Measurement methods for TSS, VSS, SCOD, TCOD, VFAs, soluble carbohydrate, soluble protein and $\mathrm{pH}$ could be found in the previous publications. ${ }^{17,20}$ VFAs were recorded as the sum of acetic (HAc), propionic (HPr), $n$-butyric ( $n$-HBu), iso-butyric (iso$\mathrm{HBu}$ ), $n$-valeric ( $n$-HVa), and iso-valeric acids (iso-HVa). Soluble carbohydrate, soluble protein and VFAs concentrations were converted to chemical demand oxygen (COD) with unit of mg COD per L. And details about COD conversion coefficients were the same as the previous publications. ${ }^{20}$ Measurement methods of currents, and both volume and component of gas produced by MECs were consistent with the researches. ${ }^{19,20}$ 


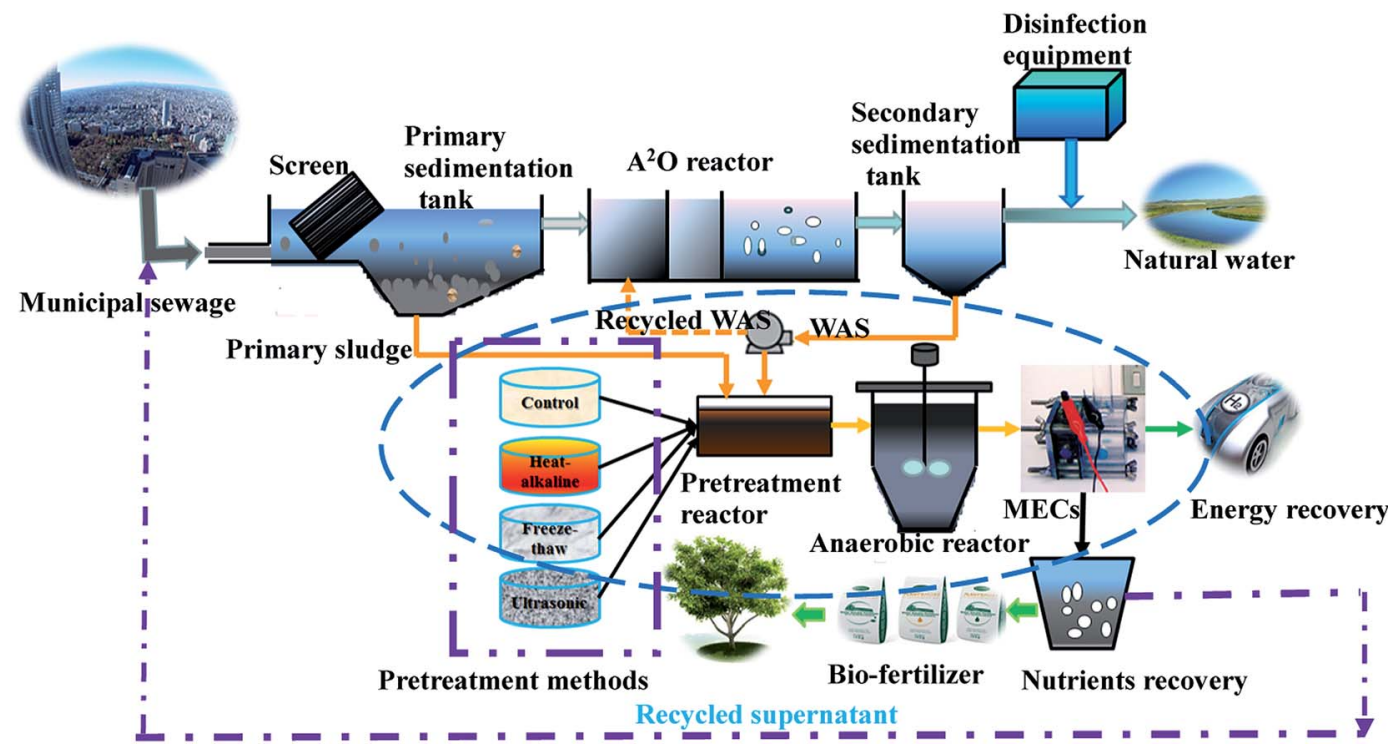

Fig. 1 Potential technique for waste activated sludge treatment.

\subsection{Calculation methods}

Both energy and coulombic efficiencies were calculated to characterize the performance of MECs. Calculation methods of energy and coulombic efficiencies were consistent with the researches. ${ }^{19,20}$ Software SPSS 17.0 had been used to analyze experimental data.

The coulombic efficiency (CE) was calculated by the following equation:

$$
\mathrm{CE}=Q_{\mathrm{C}} / Q_{\mathrm{T}} \times 100 \%
$$

where $Q_{\mathrm{C}}$ was current coulombs calculated by the equation $Q=I$ $\times t$, C and $Q_{\mathrm{T}}$ was coulombs of acetate used, C.

Energy efficiency $\left(\eta_{\mathrm{E}}\right)$ was calculated by the following equations:

$$
\begin{gathered}
\eta_{\mathrm{E}}=W_{\mathrm{H}_{2}} / W_{\mathrm{E}} \times 100 \% \\
W_{\mathrm{H}_{2}}=n \times \Delta H \\
W_{\mathrm{E}}=Q \times E_{\mathrm{ap}}
\end{gathered}
$$

where $W_{\mathbf{H}_{2}}$ was the combustion heat of hydrogen produced, $\mathrm{kJ}$, $W_{\mathrm{E}}$ was the electricity input, kJ, $n$ was the moles of hydrogen production under standard conditions, mol, $\Delta H$ was the combustion heat of $1 \mathrm{~mol}$ hydrogen, $285.83 \mathrm{~kJ} \mathrm{~mol}^{-1} \mathrm{H}_{2}$, and $E_{\text {ap }}$ was the external voltage, $0.8 \mathrm{~V}$.

The removal efficiencies of both TSS and VSS, and average reduction rate of both TSS and VSS were defined as the following equations:

$$
\begin{gathered}
\text { TSS removal }=\left(\mathrm{TSS}_{0}-\mathrm{TSS}_{t}\right) / \mathrm{TSS}_{0} \times 100 \% \\
\text { VSS removal }=\left(\mathrm{VSS}_{0}-\mathrm{VSS}_{t}\right) / \mathrm{VSS}_{0} \times 100 \% \\
V_{\mathrm{TSS}}=\left(\mathrm{TSS}_{0}-\mathrm{TSS}_{t}\right) / t
\end{gathered}
$$

$$
V_{\mathrm{VSS}}=\left(\mathrm{VSS}_{0}-\mathrm{VSS}_{t}\right) / t
$$

where $\mathrm{TSS}_{0}$ and $\mathrm{VSS}_{0}$ were the initial values, $\mathrm{g} \mathrm{L}^{-1}$, respectively, $\mathrm{TSS}_{t}$ and $\mathrm{VSS}_{t}$ were the end values, $\mathrm{g} \mathrm{L}^{-1}$, respectively, and $t$ was the operating time of AD-MECs process, 6 days.

\section{Results and discussion}

\subsection{Performance of anaerobic fermentation and MECs start- up}

The characteristics of pretreated WAS after 3 day anaerobic fermentation were shown in Table 1. As shown in Table 1, compared with control, SCOD concentrations of other three pretreatments had been greatly enhanced, indicating these three pretreatment methods could improve the WAS hydrolysis efficiently. It was consistent with the previous studies. ${ }^{22-27}$ Also it could be concluded that heat-alkaline pretreatment could perform better than both freeze-thaw and ultrasonication pretreatments, while SCOD concentration obtained in heatalkaline pretreatment were 2.4 and 1.5 times more than freeze-thaw and ultrasonication pretreatment, respectively. The possible reason was that, compared with freeze-thaw and ultrasonication pretreatments, the release of intracellular and/ or extracellular constituents from the cells and/or extracellular polymeric substances (EPSs) to suspension was more effective in heat-alkaline pretreatment, and then WAS hydrolysis/ acidification was much improved..$^{14-17,23}$ By analyzing the components of SCOD in Table 1, it was obvious that VFAs was the highest soluble component in the fermented WAS, $67.9 \%$ for control, $40.6 \%$ for heat-alkaline pretreatment, $56.1 \%$ for freeze-thaw pretreatment and $50.1 \%$ for ultrasonication pretreatment. As exhibits in Fig. 2(a), except for control pretreatment, the percentages of HAc were relatively higher than other five components of VFAs mentioned in Section 2.3, especially heat-alkaline and ultrasonication pretreatments, 
accounted for $44.4 \%$ and $45.9 \%$, respectively. Wang et al. had reported that VFAs were easy to be utilized by MECs to produce hydrogen. ${ }^{19,20}$ Thus, compared with control, the pretreatment methods had positively enhanced efficiencies of anaerobic fermentation processes of WAS, and suggested the feasible potential using fermented WAS in MECs.

Liu et al. had reported that it could obtain positive effects, while acetate was used as the carbon source for MECs start-up. ${ }^{28}$ The 12 MECs were performed as replicates using acetate for anodic biofilm enrichment. Fig. 2(b) depicts SCOD removal, coulombic efficiencies, energy efficiencies and hydrogen production rate of MECs at start-up stage. As shown in Fig. 2(b), coulombic efficiencies of all MECs were stabilized at $108.3 \pm$ $5.2 \%$, the corresponding SCOD removal and energy efficiencies were $86.1 \pm 2.1 \%$ and $121.3 \pm 9.9 \%$ with current peak $(4.12 \pm$ $0.33) \mathrm{mA}$, respectively. All MECs had similar abilities to convert acetate to hydrogen, $0.91 \pm 0.08 \mathrm{~m}^{3}$ per $\mathrm{m}^{3}$ per day at $24 \mathrm{~h}$ retention time. Results above indicated that MECs had been started up successfully. ${ }^{19}$ After MECs start-up, these 12 MECs were divided into four groups, three MECs of each group operated in parallel for hydrogen production by feeding with fermented WAS, named G1 (control pretreatment), G2 (heatalkaline pretreatment), G3 (freeze-thaw pretreatment) and G4 (ultrasonication pretreatment), respectively.

\subsection{Performance of AD-MECs on sludge reduction}

Currently, biological methods, especially anaerobic fermentation, are given priority to achieve sludge reduction..$^{\mathbf{1 , 1 0 , 1 1}}$ In this paper, effects of a novel technology, named pretreatment coupled with AD-MECs, had been investigated for sludge reduction (Fig. 3). As shown in Fig. 3(a), compared with raw WAS, TSS and VSS of experiment pretreatments were all reduced significantly, especially heat-alkaline pretreatment, the corresponding removal efficiencies were $36.9 \%$ and $46.7 \%$, respectively. Ordering the TSS and VSS reductions were heat-alkaline > ultrasonication $>$ freeze-thaw $>$ control pretreatments. This was consistent with results of anaerobic fermentation, indicating that WAS pretreatment had enhanced sludge reduction of AD-MECs process. The possible reason was that WAS hydrolysis/ acidification greatly strengthened by pretreatment, then biohydrogen production and sludge reduction by $\mathrm{AD}-\mathrm{MECs}$ process was positively enhanced. ${ }^{1,29,30}$

United States Environmental Protection Agency (USEPA) had reported that, when VSS removal efficiency was more than $38 \%$, (a)

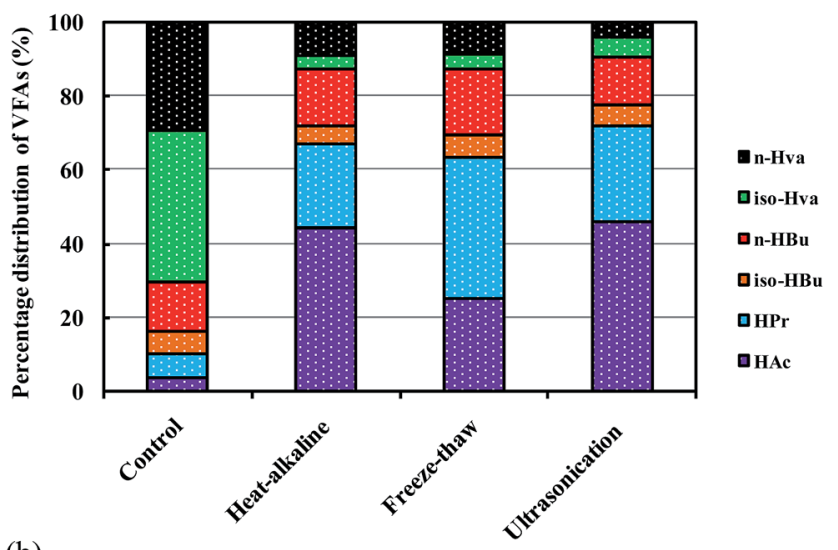

(b)

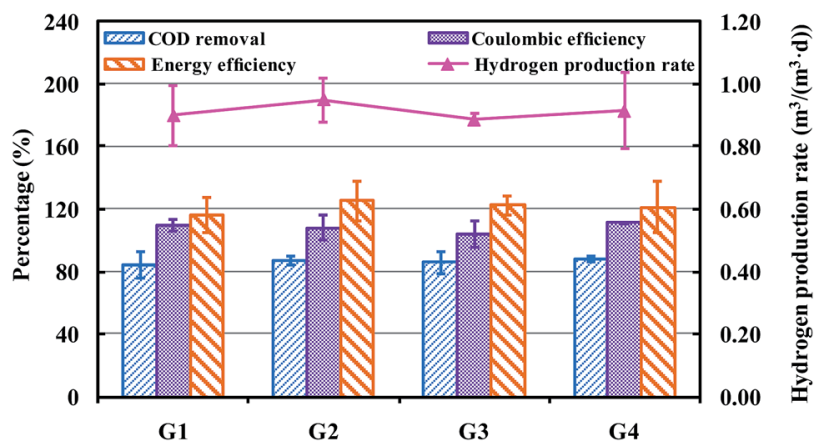

Fig. 2 Performance of anaerobic fermentation and MECs start-up. (a) Percentage distribution of VFAs of pretreated WAS after anaerobic fermentation, (b) performance of MECs start-up fed with acetate.

sludge reduction could be achieved. ${ }^{31,32}$ As shown in Fig. 3(b), both heat-alkaline and ultrasonication pretreatments coupled with $\mathrm{AD}-\mathrm{MECs}$ for sludge reduction all met the USEPA standard, $46.7 \%$ and $43.9 \%$ for VSS removal, which were 2.56 and 2.40 times more than control pretreatment, respectively. Also, sludge reductions observed in heat-alkaline and ultrasonication pretreatments were higher than $38.7 \%$ for VSS reduction observed by Xiao et al., ${ }^{33}$ who had used microbial fuel cells (MFCs) to achieve sludge reduction. So just taking sludge reduction into consideration, both processes above were better choices.

\subsection{Bio-hydrogen production and energy recovery}

In recent years, many researchers have reported biogas production from WAS by $\mathrm{AD}$ process. ${ }^{\mathbf{1 , 1 0 - 1 2 , 1 5 , 3 4 - 3 6}}$ A potential technique,

Table 1 Characteristics of pretreated WAS after 3 day anaerobic digestion ${ }^{a}$

\begin{tabular}{|c|c|c|c|c|c|}
\hline & pH, Ave. \pm St. Dev. & $\begin{array}{l}\text { VFAs (mg COD per L), } \\
\text { Ave. } \pm \text { St. Dev. }\end{array}$ & $\begin{array}{l}\text { Carbohydrate (mg COD per L), } \\
\text { Ave. } \pm \text { St. Dev. }\end{array}$ & $\begin{array}{l}\text { Protein }(\mathrm{mg} \text { COD per L), } \\
\text { Ave. } \pm \text { St. Dev. }\end{array}$ & $\begin{array}{l}\text { SCOD (mg COD per L), } \\
\text { Ave. } \pm \text { St. Dev. }\end{array}$ \\
\hline Control & $6.86 \pm 0.05$ & $416.60 \pm 45.65$ & $13.66 \pm 1.23$ & $105.45 \pm 34.22$ & $613 \pm 67$ \\
\hline Heat-alkaline & $7.93 \pm 0.17$ & $1833.31 \pm 180.87$ & $474.37 \pm 45.33$ & $1514.57 \pm 143.22$ & $4514 \pm 123$ \\
\hline Freeze-thaw & $6.76 \pm 0.15$ & $1039.36 \pm 54.33$ & $52.93 \pm 10.32$ & $453.44 \pm 86.03$ & $1854 \pm 56$ \\
\hline Ultrasonication & $6.47 \pm 0.23$ & $1507.74 \pm 98.23$ & $221.96 \pm 14.67$ & $794.32 \pm 56.00$ & $3012 \pm 150$ \\
\hline
\end{tabular}

${ }^{a}$ St. Dev. is standard deviation. And ave. is average. 
(a)

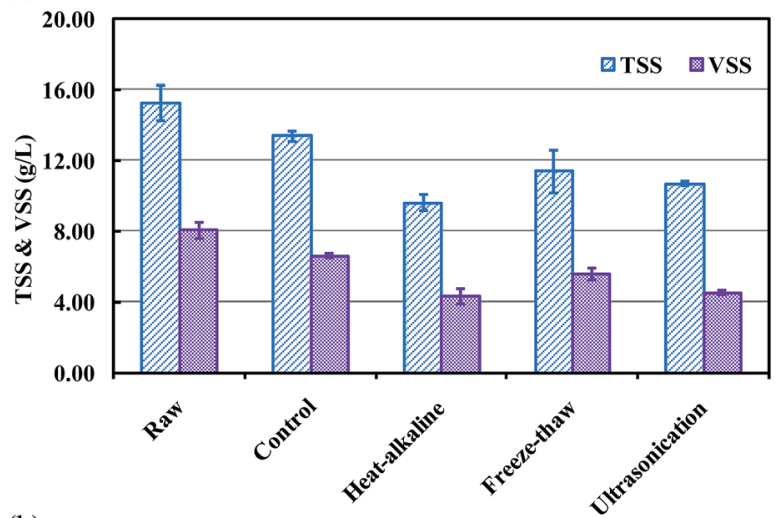

(b)

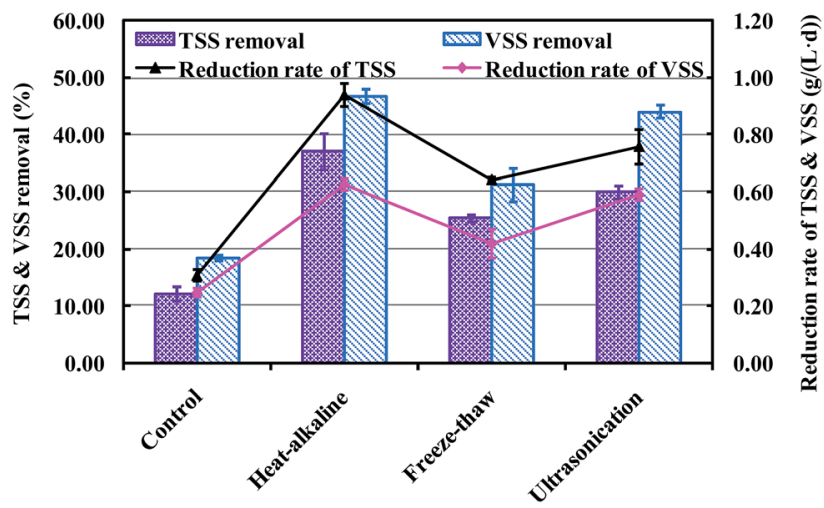

Fig. 3 Performance of AD-MECs on sludge reduction. (a) TSS and VSS changes after AD-MECs process, (b) removal efficiencies and reduction rates of TSS and VSS.

AD-MECs process, were used to enhance bio-hydrogen production by feeding pretreated WAS in this work. Fig. 4 shows the biohydrogen production and energy efficiency. As shown in Fig. 4(a), in $72 \mathrm{~h}$ retention time, the highest bio-hydrogen production rate was obtained in heat-alkaline pretreatment, $0.67 \mathrm{~m}^{3}$ per $\mathrm{m}^{3}$ per day, then followed by ultrasonication and freeze-thaw pretreatments. The possible reasons might be that, heat-alkaline pretreatment had enhanced WAS hydrolysis/acidification more effectively than the other two pretreatments, which provided the preferred substrate for MECs to produce bio-hydrogen, ${ }^{19}$ and the different initial $\mathrm{pH}$ of different fermented WAS (Table 1), might also influence the performance of MECs. ${ }^{36-38}$ Ruiz et al. had reported the effects of $\mathrm{pH}$ on hydrogen production of MECs fed with acetate, and results showed that $\mathrm{pH}$ control was beneficial for the MEC performance. ${ }^{37}$ By contrast, Kyazze et al. have reported that at an applied voltage of $850 \mathrm{mV}$, the difference in hydrogen production rates at pHs 5, 7 and 9 was however not statistically significant at the $P<0.05$ level. ${ }^{39}$ Moreover, the microbial communities in different pretreatments might be not consistent, which might further influence the performances of MECs. Sun et al. had reported difference of the microbial communities of MECs directly fed with alkaline-pretreated WAS and raw WAS, and pretreatment method had caused positive effects on microbial communities to produce hydrogen. ${ }^{40}$ Compared with the experimental pretreatments, the control pretreatment had the lowest hydrogen production rate, this may be caused by the following two reasons, on one hand, soluble organic matters, especially VFAs of control pretreatment were the lowest, leading to poorest activities of hydrogenogens in MECs, on the other hand, during the operation process, the hydrogen produced would be consumed by other microorganisms in MECs because of substrate deficiency. ${ }^{19,41}$

The highest hydrogen yield was also obtained in heatalkaline pretreatment, $20.30 \mathrm{mg} \mathrm{H}_{2} / \mathrm{g}$ VSS (Fig. 4(a)), which was 2.38 and 1.84 times more than that obtained in the previous researches reported by Liu et al. ${ }^{19}$ and Wang et al. ${ }^{20}$ Meanwhile, the bio-hydrogen yield obtained in ultrasonication pretreatment was 1.82 and 1.40 times more than that obtained in the above studies, respectively. ${ }^{19,20}$ These attractive results might be attributed to the fact, compared with fermented liquid of WAS, microbial species contained in fermented WAS were much more abundant, some fermentative bacteria first utilized various sugars and amines to produce organic acids (e.g. acetate, propionate, and butyrate), which are subsequently metabolized by exoelectrogens for electricity generation. ${ }^{41,42}$ In the researches of both Lu et al. and Sun et al., ${ }^{22,40}$ fermented WAS after alkaline pretreatment was used as substrate of MECs to produce bio-hydrogen. The bio-hydrogen yields were 15.08 $\mathrm{mg} \mathrm{H}_{2} / \mathrm{g}$ VSS and $14.2 \pm 0.4 \mathrm{mg} \mathrm{H}_{2} / \mathrm{g}$ VSS, respectively, which

(a)

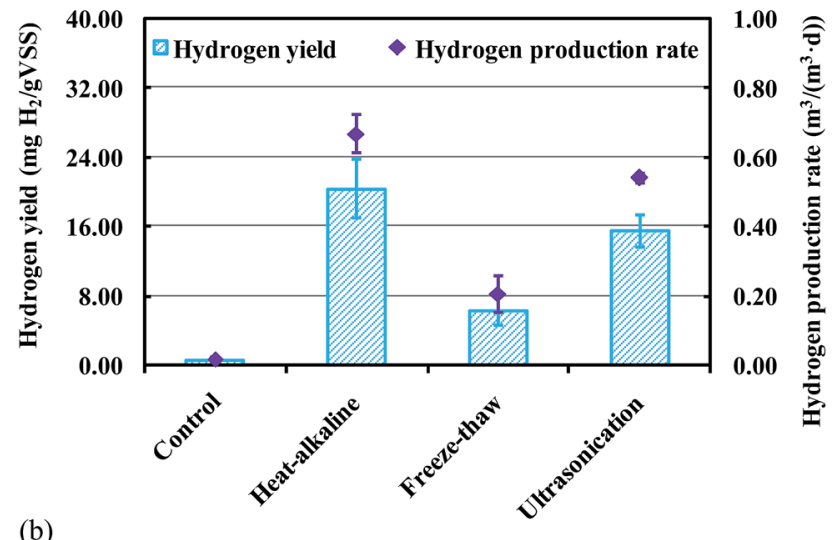

(b)

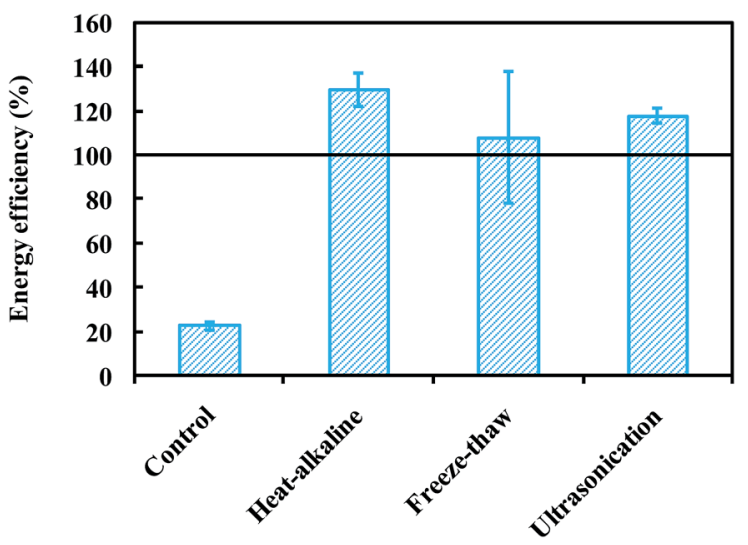

Fig. 4 Biohydrogen production and energy recovery by AD-MECs process fed with fermented WAS (a) biohydrogen production, (b) energy efficiency. 
were equivalent with ultrasonication pretreatment $(15.48 \mathrm{mg}$ $\mathrm{H}_{2} / \mathrm{g}$ VSS) of this study, but lower than that in heat-alkaline pretreatment (20.30 $\mathrm{mg} \mathrm{H}_{2} / \mathrm{g}$ VSS). This phenomenon might be attributed to the followings reasons. On one hand, compared with alkaline pretreatment, more positive effects of heatalkaline pretreatment and equivalent effects of ultrasonication pretreatment on WAS hydrolysis/acidification achieved. On the other hand, the changes of microbial communities in MECs, which were caused by fermented WAS after heat-alkaline or ultrasonication pretreatments, might be more beneficial than that of alkaline pretreatment. ${ }^{43,44}$ Therefore, heat-alkaline and ultrasonication pretreatments coupled with AD-MECs performed well for bio-hydrogen production from WAS.

As shown in Fig. 4(b), it was obvious that energy efficiencies of other three pretreatments were higher than $100 \%, 129.8 \%$, $107.9 \%$ and $117.7 \%$ for heat-alkaline, freeze-thaw and ultrasonication pretreatments, respectively. Similar conclusions could be found in previous publications, ${ }^{9,20,22}$ positive energy recovery could be realized, while using pretreated WAS as the substrate for MECs to produce bio-hydrogen. It suggested that three pretreatment methods used in this study coupled with AD-MECs for WAS treatment could achieve net energy recovery.

\subsection{Kinetic models}

In order to evaluate influences of initial concentrations of soluble protein, soluble carbohydrate, and VFAs on biohydrogen yield of MECs, and the possible relationships between TSS and VSS reduction and bio-hydrogen yields, software SPSS17.0 was used to build mathematical statistical models. As shown in Fig. 5(a), bio-hydrogen yield increased linearly with initial concentrations of soluble organic matters increased, indicating that performance of $\mathrm{AD}$ stage was positive for enhancing bio-hydrogen production in the MECs process. Relationships between initial concentrations of soluble organic matters and bio-hydrogen yields can be expressed as eqn (9) by linear regression analysis.

$$
\left\{\begin{array}{l}
Y_{\mathrm{IVFASC}}=68.17 X_{\text {hydrogen yield }}+473.53, R^{2}=0.9742 \\
Y_{\mathrm{ISPC}}=64.75 X_{\text {hydrogen yield }}+27.14, R^{2}=0.9194 \\
Y_{\mathrm{ISCC}}=22.20 X_{\text {hydrogen yield }}-45.63,27.14, \quad R^{2}=0.8903
\end{array}\right.
$$

where $Y_{\text {IVFASC }}, Y_{\text {ISPC }}$ and $Y_{\text {ISCC }}$ are initial VFAs, soluble protein, soluble carbohydrate concentrations, respectively, $\mathrm{mg} \mathrm{L}^{-1}$. And $X_{\text {hydrogen yield }}$ is bio-hydrogen yield, $\mathrm{mg} \mathrm{H}_{2} / \mathrm{g}$ VSS.

According to the kinetic slopes from eqn (9), it was obvious that initial concentrations of VFAs presented more significant effect on bio-hydrogen production, then followed by soluble protein and soluble carbohydrate. This might be due to two reasons. Firstly, VFAs were the most suitable substrate for MECs to produce hydrogen in a WAS recycling system. ${ }^{19,20,40,42}$ Secondly, VFAs could be formed from protein and carbohydrate. Chen $e$ al. had reported that HAc, $n$-HBu and HPr were formed directly from the fermentation of protein and carbohydrate, and the higher molecular weight SCFA such as $n$-HVa, were largely relevant to the fermentation of protein. ${ }^{15,45}$ Meanwhile, $n-\mathrm{HBu}$, HPr and $n$-HVa were easily biodegraded to HAc in the anaerobic fermentation system. ${ }^{45,46}$ Thus, the kinetic models above

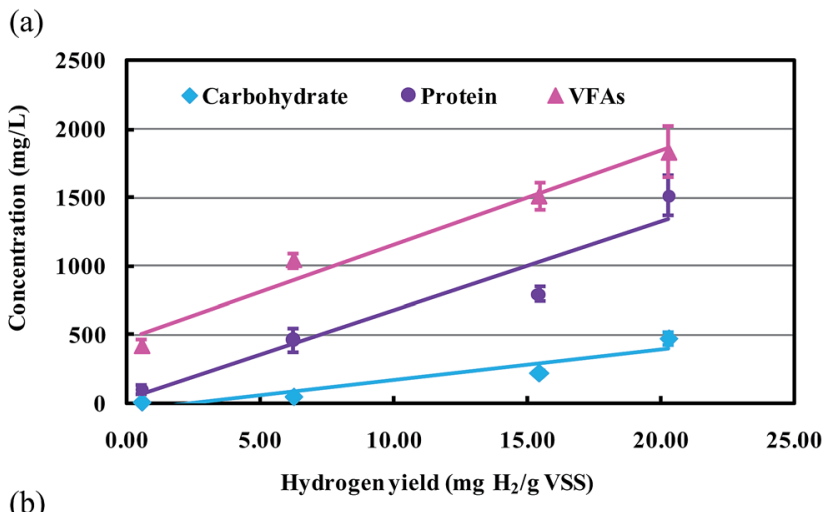

(b)

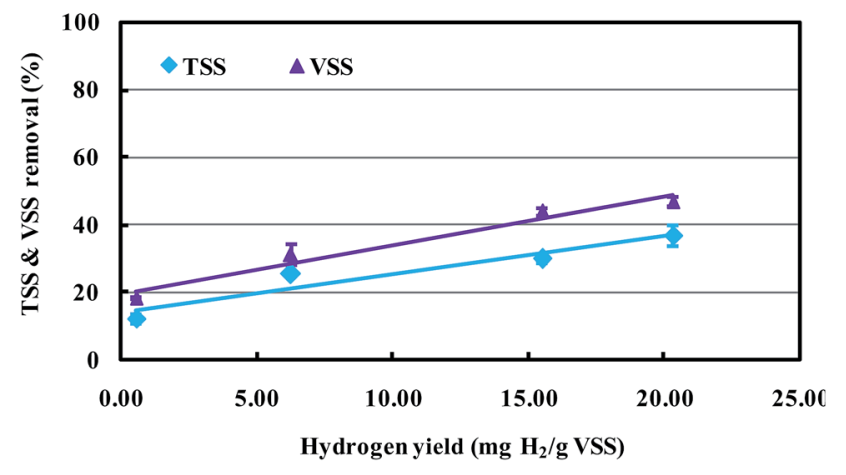

Fig. 5 Mathematical models. (a) Relationships between initial concentrations of soluble organic matters (soluble protein, carbohydrate and VFAs) and biohydrogen yields, (b) relationships between TSS and VSS reduction rates and biohydrogen yields.

indicated that the more concentrations of soluble organic matters in influent of MECs, the more bio-hydrogen produced.

Fig. 5(b) exhibits linear relationships between TSS and VSS removal efficiencies and bio-hydrogen yields. It can be observed that, VSS had higher removal efficiencies than that of TSS with same bio-hydrogen yields, meanwhile, TSS and VSS had higher removal efficiencies with higher bio-hydrogen yields. It was indicated that the organic matters of TSS and VSS were further converted to bio-hydrogen by the functional microorganisms in the MECs, resulting in an increased hydrogen production, as well as increased TSS and VSS removal efficiencies. Sun et al. had reported that the MECs fed with alkaline-pretreated WAS, had higher both hydrogen production and removal efficiencies of total solid (TS) and VSS than that fed with raw sludge. ${ }^{\mathbf{4 0}}$ The relationships between TSS and VSS removal efficiencies and biohydrogen yields can be expressed as eqn (10) by linear regression analysis.

$$
\begin{cases}Y_{\text {VSS removal }}=1.44 X_{\text {hydrogen yield }}+19.68, & R^{2}=0.9621 ; \\ Y_{\text {TSS removal }}=1.12 X_{\text {hydrogen yield }}+14.11, & R^{2}=0.9179 .\end{cases}
$$

where $Y_{\text {TSS removal }}$ and $Y_{\mathrm{VSS}}$ removal are TSS and VSS removal efficiencies, respectively, \%. And $X_{\text {hydrogen yield }}$ is hydrogen yield, $\mathrm{mg} \mathrm{H}_{2} / \mathrm{g}$ VSS.

\subsection{Outlook of this work}

A positively potential technique named pretreatment coupled with AD-MECs for renewable bio-hydrogen production and 
WAS reduction had been proposed in this work. Results showed that the process performed good efficiencies on both sludge reduction and bio-hydrogen production. The pretreatment methods were important to WAS utilization, however, few reports mentioned the subsequent effects to cascade utilization of WAS, which might be caused by initial treatment. Hereby, this study was designed to disclose the effects from WAS pretreatment to $\mathrm{AD}-\mathrm{MEC}$ coupling system.

In our previous study, we had made the fermented liquid of WAS as the substrate of MECs for hydrogen production successfully, ${ }^{19,20}$ and in the research of Sun et al., alkaline pretreated WAS was directly used as substrate for MECs to improve hydrogen recovery from WAS.$^{40}$ In the study of Lu et al., alkaline pretreated WAS after 8 day fermentation had been used as the substrate for MECs to produce hydrogen from WAS. ${ }^{41}$ Based on the previous studies, we proposed the process, named pretreatment coupled with AD-MECs, might be possible to enhance the bio-hydrogen production from WAS, and fortunately, satisfactory results (hydrogen production and sludge reduction) had been achieved from this work. Compared with our previous works, MECs directly fed with fermented sludge, was simplified, cost-effective, and efficient. ${ }^{19,20}$ Compared with the research of Sun et al. ${ }^{40}$ we had separated soluble organic matters (soluble protein, soluble carbohydrate and VFAs, especially VFAs) accumulation stage (AD process) from hydrogen production stage (MECs), the former, hydrolysis and acidification stage, could provide the primary substrate for MECs to produce hydrogen. Meanwhile, in MECs, could achieve the syntrophic interactions obtained in the research of Sun et al. ${ }^{40}$ And better performance achieved in our work had verified the positive effects of separated process. Compared with the research of Lu et al.,${ }^{41}$ we had investigated the possibility of high-solid WAS as the substrate for AD-MECs process. And according to our previous study, ${ }^{19,20}$ the operation time of $\mathrm{AD}-\mathrm{MECs}$ process had been shortened, but better performances had been achieved, in addition, the sludge reduction had been investigated.

The better performances of the process proposed in this work might be that, on one hand, the pretreatment methods used were more effective for WAS hydrolysis and acidification, and then the hydrogen production of MECs was enhanced, on the other hand, the fermented WAS in MECs could further extend the anaerobic fermentation, which might form synergy effects between fermentation bacteria and bio-hydrogen bacteria, as the latter could easily use metabolites from the former to produce bio-hydrogen, then the bio-hydrogen production was improved. Thus, the proposed process in this work for bioenergy recovery and sludge reduction was of great significance, and had application potential. However, this study just researched effects of AD-MECs process on performances of WAS reduction and bioenergy recovery. In the future, further study should be conducted to better understand the microbial response mechanisms of AD-MECs, while feeding with pretreated sludge, which was of great significance to gain insight into the proposed technology.

\section{Conclusions}

In this work, the pretreatment coupled with $\mathrm{AD}-\mathrm{MECs}$ were set up for bioenergy recovery and sludge reduction. Several interesting conclusions can be achieved as follows: (1) the maximum sludge reduction achieved in heat-alkaline pretreatment, 36.9\% and $46.7 \%$ for TSS and VSS removal, respectively. Sludge reduction of both heat-alkaline and ultrasonication pretreatments all met the USEPA standard. (2) MECs fed with fermented WAS, displayed positive potential for energy recovery, and the highest hydrogen yield and energy efficiency were $20.30 \mathrm{mg} \mathrm{H}_{2} / \mathrm{g}$ VSS and $129.8 \%$, respectively, obtained in heat-alkaline pretreatment. (3) Kinetic models, built on linear regression techniques, indicated that with initial concentrations of soluble organic matters increasing, the bio-hydrogen yields of MECs increased linearly $\left(R^{2}=0.8903-0.9742\right)$. (4) The pretreatment coupled with AD-MECs process can not only enhance sludge reduction, but also improve bio-hydrogen production, suggesting a promising technology for WAS treatment.

\section{Acknowledgements}

This research was supported by National Science Foundation for Distinguished Young Scholars (Grant no. 51225802), by Science Fund for Creative Research Groups (Grant no. 51121062), by National Natural Science Foundation of China (Grant no. 51208496), by "Hundred Talents Program" of the Chinese Academy of Sciences, and by Chinese Academy of Sciences (135 Project, Grant No. YSW2013B06), International S\&T cooperation program (S2015GR1012).

\section{References}

1 W. Q. Zhang, Q. Y. Wei, S. B. Wu, D. D. Qi, W. Li, Z. Zuo and R. J. Dong, Appl. Energy, 2014, 128, 175-183.

2 L. Brennan and P. Owende, Renewable Sustainable Energy Rev., 2010, 14, 557-577.

3 S. Shafiee and E. Topal, Energy Policy, 2009, 37, 181-189.

4 M. A. Basile, C. Carfagna, P. Cerruti, G. Gomez d'Ayala, A. Fontana, A. Gambacorta, M. Malinconico and L. Dipasquale, RSC Adv., 2012, 2, 3611-3614.

5 D. Pant, A. Singh, G. Van Bogaert, S. Irving Olsen, P. Singh Nigam, L. Diels and K. Vanbroekhoven, RSC Adv., 2012, 2, 1248-1263.

6 W. Q. Guo, S. S. Yang, J. W. Pang, J. Ding, X. J. Zhou, X. C. Feng, H. S. Zheng and N. Q. Ren, RSC Adv., 2013, 44, 21848-21855.

7 K. Christopher and R. Dimitrios, Energy Environ. Sci., 2012, 5, 6640-6651.

8 A. J. Zhou, Z. C. Guo, C. X. Yang, F. Y. Kong, W. Z. Liu and A. J. Wang, J. Biotechnol., 2013, 168, 234-239.

9 R. K. Goud and S. V. Mohan, RSC Adv., 2012, 2, 6336-6353.

10 L. Y. Jin, G. M. Zhang and H. F. Tian, Water Res., 2014, 66, 85-98.

11 S. Kavitha, C. Jayashree, S. Adish Kumar, S. Kaliappan and J. Rajesh Banu, Bioresour. Technol., 2014, 173, 32-41. 
12 D. Zhang, Y. Chen, Y. Zhao and X. Zhu, Environ. Sci. Technol., 2010, 44, 4802-4808.

13 X. Jiang, S. G. Sommer and K. V. Christensen, Energy Policy, 2011, 39, 6073-6081.

14 C. X. Yang, A. J. Zhou, Z. W. He, L. Jiang, Z. C. Guo, A. J. Wang and W. Z. Liu, Environ. Sci. Pollut. Res., 2015, 1-10.

15 C. X. Yang, W. Z. Liu, Z. W. He, S. Thangavel, L. Wang, A. J. Zhou and A. J. Wang, Bioresour. Technol., 2015, 175, 509-516.

16 H. Carrere, C. Dumas, A. Battimelli, D. J. Batstone, J. P. Delgenes, J. P. Steyer and I. Ferrer, J. Hazard. Mater., 2010, 183, 1-15.

17 A. J. Zhou, C. X. Yang, Z. C. Guo, Y. N. Hou, W. Z. Liu and A. J. Wang, Biochem. Eng. J., 2013, 77, 240-245.

18 C. X. Yang, A. J. Zhou, Y. N. Hou, X. Zhang, Z. C. Guo, A. J. Wang and W. Z. Liu, Water Sci. Technol., 2014, 70, 200-208.

19 W. Z. Liu, S. Huang, A. J. Zhou, G. Zhou, N. Ren, A. Wang and G. Zhuang, Int. J. Hydrogen Energy, 2012, 37, 13859-13864.

20 L. Wang, W. Liu, L. Kang, C. Yang, A. Zhou and A. Wang, Int. J. Hydrogen Energy, 2014, 39, 11913-11919.

21 P. Hadi, M. Xu, C. Ning, C. S. K. Lin and G. McKay, Chem. Eng. J., 2015, 260, 895-906.

22 L. Lu, D. Xing, B. Liu and N. Ren, Water Res., 2012, 46, 10151026.

23 A. Zhou, J. Du, C. Varrone, Y. Wang, A. Wang and W. Liu, Process Biochem., 2014, 49, 283-289.

24 K. Hu, J. Q. Jiang, Q. L. Zhao, D. J. Lee, K. Wang and W. Qiu, Water Res., 2011, 4, 5969-5976.

25 A. Zhou, C. Yang, F. Kong, D. Liu, Z. Chen, N. Ren and A. Wang, J. Environ. Biol., 2013, 34, 381-389.

26 L. Kang, Master thesis, Harbin Institute of Technology (HIT), China, 2013.

27 X. Zhou, G. Jiang, Q. Wang and Z. Yuan, RSC Adv., 2014, 92, 50644-50652.

28 W. Liu, A. Wang, S. Cheng, B. E. Logan, H. Yu, Y. Deng, J. Nostrand, L. Wu, Z. He and J. Zhou, Environ. Sci. Technol., 2010, 44, 7729-7735.
29 C. Bougrier, J. Delgenès and H. Carrère, Process Saf. Environ. Prot., 2006, 84, 280-284.

30 C. Jayashree, G. Janshi and I. T. Yeom, Int. J. Electrochem. Sci., 2014, 9, 5732-5742.

31 T. Cheunbarn and K. R. Pagilla, J. Environ. Biol., 2000, 126, 796-801.

32 N. M. Layden, J. Environ. Eng. Sci., 2007, 6, 19-29.

33 B. Xiao, F. Yang and J. Liu, J. Hazard. Mater., 2011, 189, 444449.

34 R. U. Rani, S. A. Kumar, S. Kaliappan, I. T. Yeom and J. R. Banu, Ultrason. Sonochem., 2014, 21, 1065-1074.

35 B. Yu, D. Zhang, A. Shan, Z. Lou, H. Yuan, X. Huang, W. Yuan, X. Dai and N. Zhu, RSC Adv., 2015, 5, 38538-38546.

36 L. Dong, Y. Zhenhong, S. Yongming and M. Longlong, Int. J. Hydrogen Energy, 2010, 35, 8234-8240.

37 Y. Ruiz, J. A. Baeza and A. Guisasola, ChemSusChem., 2015, 8, 389-397.

38 M. D. Merrill and B. E. Logan, J. Power Sources, 2009, 191, 203-208.

39 G. Kyazze, A. Popov, R. Dinsdale, S. Esteves, F. Hawkes, G. Premier and A. Guwy, Int. J. Hydrogen Energy, 2010, 35, 7716-7722.

40 R. Sun, D. Xing, J. Jia, Q. Liu, A. Zhou, S. Bai and N. Ren, Int. J. Hydrogen Energy, 2014, 39, 19912-19920.

41 L. Lu, D. Xing and N. Ren, Water Res., 2012, 46, 2425-2434.

42 L. Lu, D. Xing, T. Xie, N. Ren and B. E. Logan, Biosens. Bioelectron., 2010, 25, 2690-2695.

43 R. Tan, K. Miyanaga, K. Toyama, D. Uy and Y. Tanji, Biochem. Eng. J., 2010, 52, 151-159.

44 Y. Liu, X. Li, X. Kang, Y. Yuan and M. Du, Int. Biodeterior. Biodegradation, 2014, 94, 128-133.

45 Y. Chen, S. Jiang, H. Yuan, Q. Zhou and G. Gu, Water Res., 2007, 41, 683-689.

46 H. Yuan, Y. Chen, H. Zhang, S. Jiang, Q. Zhou and G. Gu, Environ. Sci. Technol., 2006, 40, 2025-2029. 